\title{
Pathophysiology of Age-Related Hearing Loss (Peripheral and Central)
}

\author{
Kyu-Yup Lee \\ Department of Otorhinolaryngology-Head and Neck Surgery, School of Medicine, Kyungpook National University, Daegu, Korea
}

Received January 28, 2013

Revised August 2, 2013

Accepted August 7, 2013
Age-related hearing loss (presbycusis) refers to bilaterally symmetrical hearing loss resulting from aging process. Presbycusis is a complex phenomenon characterized by audiometric threshold shift, deterioration in speech-understanding and speech-perception difficulties in noisy environments. Factors contributing to presbycusis include mitochondria DNA mutation, genetic disorders including Ahl, hypertension, diabetes, metabolic disease and other systemic diseases in the intrinsic aspects. Extrinsic factors include noise, ototoxic medication and diet. However, presbycusis may not be related to the intrinsic and extrinsic factors separately. Presbycusis affects not only the physical, cognitive and emotional activities of patients, but also their social functioning. As a result, patients' quality of life deteriorates, compounded by various symptoms including depression, social isolation and lower self-esteem. Presbycusis is classified into six categories, as based on results of audiometric tests and temporal bone pathology, established by Schuknecht (1993): sensory, neural, metabolic or strial, cochlear conductive, mixed and indeterminate types. Among these, metabolic presbycusis is the mainstay of presbycusis types. Age-related changes also develop in the central hearing system. Functional decline of the central auditory system, caused by aging, reduces speech-understanding in noisy background and increase temporal processing deficits in gap-detection measures. This study reviews the literature on the age-related hearing loss.

Korean J Audiol 2013;17:45-49

KEY WORDS: Presbycusis · Pathophyisology · Molecular genetics · Histopathology · Auditory brainstem.
Age-related hearing loss (presbycusis) refers to bilaterally symmetrical hearing loss resulting from aging process. ${ }^{1)}$ Presbycusis is a complex phenomenon characterized by audiometric threshold shift, deterioration in speech-understanding and speech-perception difficulties in noisy environment. ${ }^{1,2)}$ According to ISO 7029:2000 (International Organization for Standardization), the over-60 age group loses hearing of $1 \mathrm{~dB}$ on average per year. Hearing loss increases over time. ${ }^{1)}$ Approximately $30 \%$ of the aged population, or 9 million elderly people, suffer from hearing loss. ${ }^{3)}$ In the 2003 report by the Center for Disease Control (U.S.), presbycusis was the second most common illness next to arthritis in the aged people. Its morbidity has risen with the aging population. According to the reports of the National Statistical Office (Republic of Korea), the over-65 age population was 4.7 million in 2000 , or $7.2 \%$ of the total population. This age group is expected to rise by more than $15 \%$ by 2020 , as the pace of population-aging accelerates. The number of patients with presbycusis is expected to rise in South Korea accordingly. Factors contributing to presbycusis include mitochondria DNA mutation, genetic disorders such as $A h l$, hypertension, diabetes, metabolic disease and other systemic diseases in the intrinsic aspects. Extrinsic factors include noise, ototoxic medication and diet. It is difficult to relate presbycusis to intrinsic and extrinsic factors separately. ${ }^{1,4)}$ Presbycusis affects not only the physical, cognitive and emotional activities of patients, but also the social functioning. As a result, patients' quality of life deteriorates with various symptoms such as depression, social isolation and lowered self-esteem.

However, there is no clinical way to predict the onset of presbycusis in advance. There is neither medical prevention nor treatment that can restore hearing loss at this time. ${ }^{6}$

Since conductive high-tone hearing loss occurs due to stiffness and laxity of eardrum and its attached ossicles in middle 
ear by aging process, such hearing loss does not affect significantly on the hearing level. ${ }^{7)}$

Presbycusis is commonly classified into four categories based on results of audiometric tests and temporal bone pathology as established by Schuknecht (1969): sensory, neural, metabolic or strial and cochlear conductive types. In 1993, mixed and indeterminate types were added for six categories. $^{2,8)}$

Sensory presbycusis stems from degenerating organ of Corti, which elicits hearing loss in the high-frequency range. This symmetrical hearing loss usually occurs in middle-age population. Sensory presbycusis is primarily caused by damaged outer hair cells, in $10 \mathrm{~mm}$ at the basal turn of the cochlear. Outer hair cell loss is the most prominent change in both human $^{2,8,9)}$ and animal studies., ${ }^{3,10,11)}$ In an animal model of C57BL/6J mice, outer hair cell loss expanded from the basal turn to apex, while the progressive hearing loss began in the

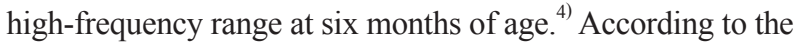
Schuknecht Classifications, the incidence of sensory presbycusis accounted for $5 \%$ of the total presbycusis cases. The incidence of sensory presbycusis was also not high in the study by Gates, et al., using a DPOAE study. ${ }^{12)}$

Neural presbycusis shows a moderate downward slope of pure tone threshold toward high-frequency and a severe decrease in speech discrimination compared to pure tone threshold. ${ }^{2)}$ Based on histological data, the loss of $50 \%$ or more of 35500 cochlear neurons is used as the criteria for neural presbycusis. Otte, et al. ${ }^{13)}$ demonstrated that approximately 2100 neurons were lost every 10 years in human. The loss of $50 \%$ of afferent nerve results in decreased speech discrimination, and $90 \%$ of loss elicits a change in hearing threshold. ${ }^{14,15}$ )

Strial or metabolic presbycusis shows hearing loss across all frequency range in audiogram. Metabolic ARHL is caused by the atrophy of the stria vascularis: the loss of $30 \%$ or more of the tissue in the stria vascularis results in a decrease in hearing threshold. ${ }^{16)}$ The loss of strial tissue causes $\mathrm{K}^{+}$recycling disorder, resulting in a decrease in endolymphatic potential. The frequency range is therefore affected as a whole. One of six subjects in Schuknecht's temporal bones exhibited metabolic presbycusis. Mills cited metabolic type as the main cause of presbycusis. ${ }^{2,17)}$ It is known that high-frequency hearing loss is highly associated with the loss of endolymphatic potential, and that the degree of loss is a crucial factor. ${ }^{18)}$ Animal studies demonstrated degeneration of stria vascularis and decreased endolymphatic potential along with hearing loss in gerbil. ${ }^{18-20)}$ Also, severe degeneration of spiral ligament was observed in autosomal-dominant non-syndromic hearing loss (DFNA9) among genetic hearing loss. ${ }^{21)}$

Cochlear conductive presbycusis is described as a degener- ative change resulting from the stiffness in the basal area of the cochlear. It is said that this type of presbycusis is manifested by a low-frequency hearing loss, with unimpaired speech recognition. However cochlear conductive presbycusis has not been verified as yet. ${ }^{2)}$

Mixed presbycusis refers to a combination of these types of hearing loss. It is characterized by a smooth down-slope hearing loss toward high-frequency and an abrupt increase in threshold at the high frequencies. Also loss of outer hair cells in $10 \mathrm{~mm}$ at the basal area of the cochlear is observed along with severe loss of cochlear neurons (50\% or more) and stria vascularis (30\% or more). ${ }^{2)}$ Low-tone hearing loss is stemmed from disorder of the stria vascularis, while high-tone hearing loss is caused by loss of outer hair cells. ${ }^{2)}$

Indeterminate hearing loss refers no correlation between audiometric pattern and pathologic alterations in cochlea, although no abnormality is microscopically observed in the cochlear tissue. ${ }^{2,9,22)}$ The incidence of indeterminate hearing loss was as high as $25 \%$ of total cases in Schuknecht's study on temporal bones. ${ }^{2)}$ Indeterminate type appears to result from microstructural damage in the tip links of stereocilia and mechanoelectrical transduction channels and from the central hearing impairment, although the cochlear tissue shows no abnormalities under optical microscopy. ${ }^{23)}$

Critics of Schuknecht's typology have claimed that most presbycusis types cannot be clearly classified by histopathological data and that the results are confused accordingly. ${ }^{3)}$ They have also pointed out the lack of data on the role of non-epithelial cells apart from outer hair cell in the cochlear and the change in the central hearing system apart from peripheral auditory system. ${ }^{3)}$ In addition, the atrophy or rupture of the cochlear tissue, which were described as changes in Reissner's membrane by aging process, has also been referred to as the cause of presbycusis. $^{24,25)}$

As seen, presbycusis may be caused by various medical disorders. Age-related vascular disorders are found in either cochlear or spiral ligaments, while metabolic diseases such as diabetes may also cause vascular changes. ${ }^{4)}$

Changes in voltage-gated K-channel subunits Kv1.1 and Kv3.1 were observed in cochlear neurons in aging. ${ }^{26)}$ Glycineevoked changes that affect hyperpolarizing action were found in cochlear nucleus in aged C57 mice and Fischer 344 rats. $^{27)}$ Also, age-related changes in receptors of glutamate neurotransmitters, which are released upon depolarization in auditory neurons, have been found in the hearing nerves. ${ }^{28)}$ A study suggested that calcium-binding proteins such as parvalbumin, calretinin and calbindin, which increased with age in cochlear nucleus, led to degeneration of the cochlea. ${ }^{29,30)}$ Activity of glial fibrillary acid proteins, which maintain cellular func- 
tion, is known to reduce cochlear nucleus during aging process in mice. ${ }^{31)}$ Age-related changes were observed in growth factors including insulin like growth factor-1, platelet-derived nerve growth factor, transforming growth factor- $\beta 1$, acidic fibroblast growth factor and brain-derived neurotrophic factor. Age-related down regulation of growth-associated protein-43 was discovered in cochlear nucleus. ${ }^{32,33)}$

Effect of oxidative stress is one of the major causes of agingrelated hearing loss. Antioxidant enzymes such as enzymes of glutathione metabolism, catalase and methionine sulfoxide reductase were found in the cochlear. ${ }^{34)}$ Presbycusis occurred in functional null mice related to glutathione peroxidase and glutathione S-transferase $\mathrm{Mu} 1 .^{35)}$

Age-related changes also develop in the central auditory system. Nearly $20 \%$ neuronal loss was discovered in vestibulocochlear nerve in rats, especially in the superior olivary complex. $^{36)}$

Age-related decrease in inhibitory effects of the medial olivary complex results in loss of contralateral suppression of DPOAE ${ }^{37,38)}$ Functional decline of the central auditory system, caused by aging, reduces speech understanding in noisy environment and increase temporal processing deficits in the gap-detection measures. ${ }^{39)}$

Age-related changes in the central nervous system result from the functional changes of neurotransmitters and synapses rather than loss of neurons. Additionally, age-related decline in concentration, memory and cognitive functions should also be considered as contributing factors in presbycusis. ${ }^{3)}$

The cochlear nucleus is responsible for analysis of sound features, including frequency, sound intensity and temporal cue in the central hearing system, In C57 mice in which early presbycusis occurred, changes in sensitivity were found in the ventral cochlear nucleus. Also aging-related changes in coding intensity developed in the dorsal cochlear nucleus in addition to the loss of glycinergic inhibition in the ventral cochlear nucleus of Fischer 344 rats. ${ }^{40}$

The superior olivary complex is responsible for various functions, including encoding temporal features of sound and localizing sound by receiving inputs from the cochlear nucleus on both sides. ${ }^{41)}$ The superior olivary complex is composed of three nuclei: medial superior olive, lateral superior olive and medical nucleus of trapezoid body. Binaural sound inputs are first processed in the lateral superior olive. The activity of glycine and gamma-amino butyric acid (GABA) decreased with increasing age in gerbils. ${ }^{42)}$ The medical nucleus of trapezoid body receives excitatory synaptic inputs. Activation of Kv3.1 potassium channel declined in this medical area as presbycusis occurred in C57BL6. ${ }^{43)} \mathrm{An}$ increase in nitric oxide was observed in Djungarian dwarf hamster with agerelated hearing loss. ${ }^{44)}$ Inhibitory GABA in olivary complex allows outer hair cells to maintain cellular activity, and in the inferior colliculus functions to localize sound. Loss of GABAassociated neuron was found in Fischer 344 with age-related hearing loss. ${ }^{45,46)}$

Genetic factors are the most critical factors that influence age-related hearing loss among the complicate multiple-causes presbycusis. The Framingham cohort study showed heritability is greater in metabolic presbycusis. ${ }^{47)}$ The heritability of metabolic presbycusis was $53 \%$ between sister to sister and $36 \%$ between mother and daughter. Male twins showed heritability of $47 \%$ in a Swedish twin study. The heritability of $61 \%$ was reported in an American study. ${ }^{48)}$ Genes are responsible for forms of monogenic hearing loss which play a role in presbycusis. Presbycusis-related genes have been identified, including ten age-related hearing loss genes, mitochondrial DNA mutation and gene modifiers. Hearing loss-related genes including SNPs in KCNQ4, NAT2*6A polymorphism, grainyhead-like 2 gene, Glutamate receptor- 7 gene and common' 4977-bp mitochondrial DNA deletion were identified through genome-wide association studies. ${ }^{49)}$

Oxidative phosphorylation to generate ATP occurs in mitochondrial respiratory chain resulting in energy production in the body, but mitochondrial dysfunction induces hearing loss by affecting apoptosis, calcium imbalance and oxygen free radical. Mice with mutations of mitochondrial DNA showed early presbycusis and a neuronal loss in the dorsal cochlear nucleus and the posterior ventral cochlear nucleus. ${ }^{50}$ MtDNA4834 was related to presbycusis in rodents and $\mathrm{mtD}$ NA4977 in human.

In mice model, 19 inbred strains exhibited presbycusis. ${ }^{51-54)}$ Of these, 10 strains had Ahl (age-related hearing loss) locus on chromosome $10 .{ }^{55)} \mathrm{Ahl}$ that encodes cadherin- 23 was found as a core gene in $\mathrm{C} 57 \mathrm{BL} / 6 \mathrm{~J}$ mice. $\mathrm{C} 57 \mathrm{BL} / 6 \mathrm{~J}$ mice were used as a key model for presbycusis, as they developed high-frequency hearing loss at six months of age, low-frequency hearing loss at 12 months and whole-frequency profound hearing loss at 15 months. ${ }^{4)}$ The progression of hearing loss was closely associated with histological changes in the cochlea. The loss of the dorsal cochlear neuron, which appears in some types of presbycusis, showed an association with the loss of peripheral outer hair cells in C57BL/6J. ${ }^{56)}$

In addition to Ahl, Ahl 3 and Ahl-resistance alleles such as Ahl 2, Ahl 4 and Ahl 8 were also discovered. CBA/J mice have Ahl-resistant allele and have shown high-tone hearing loss developing at 12 months of age. The mice began to have the loss of outer hair cells at 18 months but did not exhibit abnormal findings of stria vascularis until 25 months of age. They 
are therefore suitable as models for sensory and neural presbycusis. ${ }^{57)} \mathrm{CBA} / \mathrm{CaJ}$ mice are widely used as models for metabolic or strial presbycusis, as they develop hearing loss early with declined endocochlear potential. ${ }^{4)} \mathrm{DBA} / 2 \mathrm{~J}$ mice developed hearing loss at two months of age by showing the loss of outer hair cells and cochlear ganglion. They have Ahl genes as well. ${ }^{4)}$ BALB/cJ mice, models for metabolic presbycusis, began to have progressive hearing loss at 19 months of age and a decrease in endocochlear potential. Fischer 344 albino rats developed a rapidly progressive hearing loss at 12 months of age with the loss of outer hair cells and the stria vascularis. ${ }^{4,58)}$

As models for metabolic presbycusis, Mongolian gerbils share similar pathological characteristics as humans. The atrophy of stria vascularis and spinal ligaments and a decline of endocochlear potential were observed in the gerbils. ${ }^{19,59)}$ Chinchillas have aged-related hearing loss similar to humans but the long life span of 20 years poses a limitation for the presbycusis studies.

\section{Conclusion}

Presbycusis is the most common cause of hearing loss in the elderly population. Metabolic presbycusis is the mainstay of presbycusis types. Presbycusis develops and is exacerbated by various factors, including heredity, medical disease and environmental factors, showing various and complex clinical manifestations. There are still debates on which part of the inner ear is most affected by the aging process and which area is the most important for hearing. The prevention and treatment of presbycusis remain difficult. Further study is necessary in view of the rapidly aging population in Korea.

\section{Acknowledgments}

This research was supported by the Basic Science Research Program through the National Research Foundation of Korea (NRF) funded by the Ministry of Education, Science and Technology (2011-0009674).

\section{REFERENCES}

1) Liu XZ, Yan D. Ageing and hearing loss. J Pathol 2007;211:188-97.

2) Merchant SN, Nadol Jr JB. Schuknecht's pathology of the ear. 3rd ed. Shelton, CT: People's Medical Pub. House-USA;2010.

3) Ohlemiller KK. Age-related hearing loss: the status of Schuknecht's typology. Curr Opin Otolaryngol Head Neck Surg 2004;12:439-43.

4) Fetoni AR, Picciotti PM, Paludetti G, Troiani D. Pathogenesis of presbycusis in animal models: a review. Exp Gerontol 2011;46:41325.

5) Mulrow CD, Aguilar C, Endicott JE, Velez R, Tuley MR, Charlip WS, et al. Association between hearing impairment and the quality of life of elderly individuals. J Am Geriatr Soc 1990;38:45-50.

6) Gates GA, Mills JH. Presbycusis. Lancet 2005;366:1111-20.

7) Chisolm TH, Willott JF, Lister JJ. The aging auditory system: anatomic and physiologic changes and implications for rehabilitation.
Int J Audiol 2003;42 Suppl 2:2S3-10.

8) Schuknecht HF, Gacek MR. Cochlear pathology in presbycusis. Ann Otol Rhinol Laryngol 1993;102(1 Pt 2):1-16.

9) Suga F, Lindsay JR. Histopathological observations of presbycusis. Ann Otol Rhinol Laryngol 1976;85(2 pt.1):169-84.

10) Bhattacharyya TK, Dayal VS. Influence of age on hair cell loss in the rabbit cochlea. Hear Res 1989;40:179-83.

11) Wright A, Davis A, Bredberg G, Ulehlova L, Spencer H. Hair cell distributions in the normal human cochlea. Acta Otolaryngol Suppl 1987;444:1-48.

12) Gates GA, Mills D, Nam BH, D’Agostino R, Rubel EW. Effects of age on the distortion product otoacoustic emission growth functions. Hear Res 2002;163:53-60.

13) Otte J, Schunknecht HF, Kerr AG. Ganglion cell populations in normal and pathological human cochleae. Implications for cochlear implantation. Laryngoscope 1978;88(8 Pt 1):1231-46.

14) Makary CA, Shin J, Kujawa SG, Liberman MC, Merchant SN. Agerelated primary cochlear neuronal degeneration in human temporal bones. J Assoc Res Otolaryngol 2011;12:711-7.

15) Pauler M, Schuknecht HF, Thornton AR. Correlative studies of cochlear neuronal loss with speech discrimination and pure-tone thresholds. Arch Otorhinolaryngol 1986;243:200-6.

16) Pauler M, Schuknecht HF, White JA. Atrophy of the stria vascularis as a cause of sensorineural hearing loss. Laryngoscope 1988;98: 754-9.

17) Mills DM, Schmiedt RA. Metabolic presbycusis: differential changes in auditory brainstem and otoacoustic emission responses with chronic furosemide application in the gerbil. J Assoc Res Otolaryngol 2004;5:1-10.

18) Schulte BA, Schmiedt RA. Lateral wall Na,K-ATPase and endocochlear potentials decline with age in quiet-reared gerbils. Hear Res 1992;61:35-46.

19) Gratton MA, Smyth BJ, Lam CF, Boettcher FA, Schmiedt RA. Decline in the endocochlear potential corresponds to decreased $\mathrm{Na}, \mathrm{K}$ ATPase activity in the lateral wall of quiet-aged gerbils. Hear Res 1997;108:9-16.

20) Gratton MA, Schulte BA, Smythe NM. Quantification of the stria vascularis and strial capillary areas in quiet-reared young and aged gerbils. Hear Res 1997;114:1-9.

21) Merchant SN, Linthicum FH, Nadol JB Jr. Histopathology of the inner ear in DFNA9. Adv Otorhinolaryngol 2000;56:212-7.

22) Nelson EG, Hinojosa R. Presbycusis: a human temporal bone study of individuals with downward sloping audiometric patterns of hearing loss and review of the literature. Laryngoscope 2006;116(9 Pt 3 Suppl 112):1-12.

23) Willott JF. Effects of sex, gonadal hormones, and augmented acoustic environments on sensorineural hearing loss and the central auditory system: insights from research on C57BL/6J mice. Hear Res 2009;252:89-99.

24) Johnsson LG. Reissner's membrane in the human cochlea. Ann Otol Rhinol Laryngol 1971;80:425-38.

25) Johnsson LG. [Degenerative changes in the aging inner ear, with special reference to vascular pathology, as seen in surface preparations of the human cochlea]. Arch Klin Exp Ohren Nasen Kehlkopfheilkd 1971;200:318-30.

26) Jung DK, Lee SY, Kim D, Joo KM, Cha CI, Yang HS, et al. Age-related changes in the distribution of Kv1.1 and Kv3.1 in rat cochlear nuclei. Neurol Res 2005;27:436-40.

27) Krenning J, Hughes LF, Caspary DM, Helfert RH. Age-related glycine receptor subunit changes in the cochlear nucleus of Fischer-344 rats. Laryngoscope 1998;108(1 Pt 1):26-31.

28) Wang Y, Manis PB. Synaptic transmission at the cochlear nucleus endbulb synapse during age-related hearing loss in mice. J Neurophysiol 2005;94:1814-24.

29) Idrizbegovic E, Canlon B, Bross LS, Willott JF, Bogdanovic N. The total number of neurons and calcium binding protein positive neu- 
rons during aging in the cochlear nucleus of $\mathrm{CBA} / \mathrm{CaJ}$ mice: a quantitative study. Hear Res 2001;158:102-15.

30) Idrizbegovic E, Salman H, Niu X, Canlon B. Presbyacusis and calcium-binding protein immunoreactivity in the cochlear nucleus of BALB/c mice. Hear Res 2006;216-217:198-206.

31) Jalenques I, Burette A, Albuisson E, Romand R. Age-related changes in GFAP-immunoreactive astrocytes in the rat ventral cochlear nucleus. Hear Res 1997;107:113-24.

32) Illing RB, Horväth $M$, Laszig R. Plasticity of the auditory brainstem: effects of cochlear ablation on GAP-43 immunoreactivity in the rat. J Comp Neurol 1997;382:116-38.

33) Schmoll H, Ramboiu S, Platt D, Herndon JG, Kessler Ch, PopaWagner A. Age influences the expression of GAP-43 in the rat hippocampus following seizure. Gerontology 2005;51:215-24.

34) Strange RC, Spiteri MA, Ramachandran S, Fryer AA. GlutathioneS-transferase family of enzymes. Mutat Res 2001;482:21-6.

35) Rabinowitz PM, Pierce Wise J Sr, Hur Mobo B, Antonucci PG, Powell C, Slade M. Antioxidant status and hearing function in noise-exposed workers. Hear Res 2002;173:164-71.

36) Hoeffding V, Feldman ML. Changes with age in the morphology of the cochlear nerve in rats: light microscopy. J Comp Neurol 1988;276: $537-46$.

37) Mazelová J, Popelar J, Syka J. Auditory function in presbycusis: peripheral vs. central changes. Exp Gerontol 2003;38:87-94.

38) Kim S, Frisina DR, Frisina RD. Effects of age on contralateral suppression of distortion product otoacoustic emissions in human listeners with normal hearing. Audiol Neurootol 2002;7:348-57.

39) Hamann I, Gleich O, Klump GM, Kittel MC, Strutz J. Age-dependent changes of gap detection in the Mongolian gerbil (Meriones unguiculatus). J Assoc Res Otolaryngol 2004;5:49-57.

40) Caspary DM, Ling L, Turner JG, Hughes LF. Inhibitory neurotransmission, plasticity and aging in the mammalian central auditory system. J Exp Biol 2008;211(Pt 11):1781-91.

41) Heffner RS, Heffner HE. Sound localization, use of binaural cues and the superior olivary complex in pigs. Brain Behav Evol 1989;33:24858.

42) Gleich $\mathrm{O}$. The distribution of $\mathrm{N}$-acetylgalactosamine in the cochlear nucleus of the gerbil revealed by lectin binding with soybean agglutinin. Hear Res 1994;78:49-57.

43) von Hehn CA, Bhattacharjee A, Kaczmarek LK. Loss of Kv3.1 tonotopicity and alterations in cAMP response element-binding protein signaling in central auditory neurons of hearing impaired mice. $\mathrm{J}$ Neurosci 2004;24:1936-40.

44) Reuss S, Schaeffer DF, Laages MH, Riemann R. Evidence for increased nitric oxide production in the auditory brain stem of the aged dwarf hamster (Phodopus sungorus): an NADPH-diaphorase histochemical study. Mech Ageing Dev 2000;112:125-34.
45) Caspary DM, Raza A, Lawhorn Armour BA, Pippin J, Arnerić SP. Immunocytochemical and neurochemical evidence for age-related loss of GABA in the inferior colliculus: implications for neural presbycusis. J Neurosci 1990;10:2363-72.

46) Helfert RH, Sommer TJ, Meeks J, Hofstetter P, Hughes LF. Age-related synaptic changes in the central nucleus of the inferior colliculus of Fischer-344 rats. J Comp Neurol 1999;406:285-98.

47) Gates GA, Couropmitree NN, Myers RH. Genetic associations in age-related hearing thresholds. Arch Otolaryngol Head Neck Surg 1999;125:654-9.

48) Karlsson KK, Harris JR, Svartengren M. Description and primary results from an audiometric study of male twins. Ear Hear 1997;18: $114-20$.

49) Van Eyken E, Van Camp G, Van Laer L. The complexity of age-related hearing impairment: contributing environmental and genetic factors. Audiol Neurootol 2007;12:345-58

50) Niu X, Trifunovic A, Larsson NG, Canlon B. Somatic mtDNA mutations cause progressive hearing loss in the mouse. Exp Cell Res 2007; 313:3924-34.

51) Johnson KR, Longo-Guess C, Gagnon LH, Yu H, Zheng QY. A locus on distal chromosome 11 (ahl8) and its interaction with Cdh23 ahl underlie the early onset, age-related hearing loss of DBA/2J mice. Genomics 2008;92:219-25.

52) Johnson KR, Zheng QY, Noben-Trauth K. Strain background effects and genetic modifiers of hearing in mice. Brain Res 2006;1091:79-88.

53) Johnson KR, Gagnon LH, Webb LS, Peters LL, Hawes NL, Chang $\mathrm{B}$, et al. Mouse models of USH1C and DFNB18: phenotypic and molecular analyses of two new spontaneous mutations of the Ush1c gene. Hum Mol Genet 2003;12:3075-86.

54) Johnson KR, Erway LC, Cook SA, Willott JF, Zheng QY. A major gene affecting age-related hearing loss in C57BL/6J mice. Hear Res 1997;114:83-92

55) Johnson KR, Zheng QY, Erway LC. A major gene affecting age-related hearing loss is common to at least ten inbred strains of mice. Genomics 2000;70:171-80.

56) Idrizbegovic E, Viberg A, Bogdanovic N, Canlon B. Peripheral cell loss related to calcium binding protein immunocytochemistry in the dorsal cochlear nucleus in $\mathrm{CBA} / \mathrm{CaJ}$ mice during aging. Audiol Neurootol 2001;6:132-9.

57) Sha SH, Kanicki A, Dootz G, Talaska AE, Halsey K, Dolan D, et al. Age-related auditory pathology in the CBA/J mouse. Hear Res 2008; 243:87-94.

58) Popelar J, Groh D, Pelánová J, Canlon B, Syka J. Age-related changes in cochlear and brainstem auditory functions in Fischer 344 rats. Neurobiol Aging 2006;27:490-500.

59) Mills JH, Schmiedt RA, Kulish LF. Age-related changes in auditory potentials of Mongolian gerbil. Hear Res 1990;46:201-10. 